\title{
Inhibition of neuropeptide Y Y1 receptor induces osteoblast differentiation in MC3T3-E1 cells
}

\author{
MOTOKI YAHARA $^{1,2}$, KANCHU TEI $^{2}$ and MASATO TAMURA ${ }^{1}$ \\ Departments of ${ }^{1}$ Biochemistry and Molecular Biology and ${ }^{2}$ Oral and Maxillofacial Surgery, \\ Graduate School of Dental Medicine, Hokkaido University, Sapporo, Hokkaido 060-8586, Japan
}

Received January 18, 2017; Accepted May 3, 2017

DOI: $10.3892 / \mathrm{mmr} .2017 .6866$

\begin{abstract}
Neuropeptide Y (NPY) is a major neural signaling molecule. NPY is produced by peripheral tissues, such as osteoblasts, and binds to the corresponding $\mathrm{Y} 1$ receptor that belongs to the G-protein-coupled receptor family. Osteoblast-specific Y1 receptor knockout mice exhibit high bone mass, indicating a role of the NPY-Y1 receptor axis in the regulation of bone homeostasis. In the bone microenvironment, peripheral nerve fibers and osteoblasts produce NPY. However, the effects of the Y1 receptor on osteoblasts remain unexplored. In the present study, an RNA interference approach was employed to target the Y1 receptor, in order to determine whether it may function to regulate the growth, differentiation and viability of osteoblasts. Knockdown of the Y1 receptor by small interfering RNA (siRNA) lead to induction of alkaline phosphatase (ALP) activity and mineralization in mouse MC3T3-E1 osteoblast cells. In addition, the mRNA expression levels of ALP, osteocalcin, collagen (I) $\alpha 1$, and bone sialoprotein were significantly increased following transfection of a Y1 receptor siRNA. Furthermore, the mRNA expression levels of Runx2 and osterix were significantly increased; however, no significant alterations in cell proliferation and caspase-3/7 activity were observed in Y1 receptor siRNA-transfected cells when compared with non-targeting controls. The results demonstrate that Y1 receptor inhibition may increase osteoblastic differentiation, which indicates a role of the Y1 receptor in the regulation of osteoblastic differentiation.
\end{abstract}

\section{Introduction}

Neuropeptide Y (NPY) is a 36-amino acid peptide neurotransmitter that is widely distributed throughout the central and

Correspondence to: Professor Masato Tamura, Department of Biochemistry and Molecular Biology, Graduate School of Dental Medicine, Hokkaido University, North 13, West 7, Sapporo, Hokkaido 060-8586, Japan

E-mail: mtamura@den.hokudai.ac.jp

Key words: neuropeptide Y, osteoblast, osteoblastic differentiation, Y1 receptor peripheral nervous systems $(1,2)$. In the central nervous system, NPY has been implicated in controlling appetite and energy homeostasis (3). In the peripheral nervous system, NPY functions as part of the sympathetic nervous system, where it is co-stored and co-released with noradrenaline during nerve stimulation (3). In addition, several cell types that produce NPY have been identified, such as osteoblasts and adipocytes (4-6). In addition, NPY regulates bone homeostasis via direct and indirect mechanisms $(7,8)$.

NPY receptors are members of the G-protein-coupled receptor superfamily. The following five subtypes have been identified thus far: Y1, Y2, Y4, Y5, and Y6 (9), of which, Y1 and $\mathrm{Y} 2$ receptors modulate bone mass in mice (10). Germline deletion of either the $\mathrm{Y} 1$ or $\mathrm{Y} 2$ receptor affects similar anabolic effects in bones, which leads to increased bone mass due to activated osteoblasts and an augmented rate of bone formation $(5,11)$. However, the mechanisms underlying the function of the Y1 receptor compared with that of the Y2 receptor in bone tissues appear to differ. Germline and conditional hypothalamic Y2 receptor deletion mice share the same high-bone-mass phenotype, indicating that the central hypothalamic Y2 receptor is crucial for this phenotype $(11,12)$. By contrast, the bone tissue is unaltered by conditional knockout of the hypothalamic Y1 receptor, indicating a non-hypothalamic control of bone mass by this receptor subtype (5).

A number of previous studies have demonstrated that NPY and Y1 receptors are directly involved in regulating osteoblasts. Y1 receptor expression has been detected in osteoblastic cells lining endocortical and trabecular bone surfaces (13), as well as in cultured primary calvarial osteoblasts (14). In a previous report, Kurebayashi et al (15) demonstrated that bone morphogenetic protein (BMP) 2 induced $\mathrm{Y} 1$ receptor expression in myoblastic $\mathrm{C} 2 \mathrm{C} 12$ cells. This induction was additionally observed following co-transfection with Smad1 and Smad4, which are intracellular signaling molecules of the BMP2 signaling pathway, indicating that $\mathrm{Y} 1$ receptor expression depends upon osteoblast differentiation (15). Mice lacking the Y1 receptor in specific osteoblasts have a high bone mass phenotype similar to that of germline Y1 receptor-null mice (16). This suggests that the Y1 receptor mediates functions in the bone via direct actions on osteoblasts, and that the osteoblastic Y1 receptor serves a role in the regulation of bone homeostasis (16). NPY inhibits the cyclic adenosine monophosphate response to parathyroid hormone 
and norepinephrine in cultured osteoblastic cell lines $(7,17)$. In addition, treatment of cultured osteoblasts or bone marrow stromal cells with NPY reduces markers of osteoblast differentiation (7). However, although the Y1 receptor is expressed in osteoblasts, it is unclear whether the osteoblastic Y1 receptor regulates osteoblast differentiation.

The aim of the present study was to investigate the role of the Y1 receptor in mediating osteoblast differentiation. To achieve this, RNA-interference was employed to silence the expression of mouse MC3T3-E1 cells.

\section{Materials and methods}

Cell cultures. The mouse MC3T3-E1 osteoblast cell line was obtained from RIKEN BioResource Center (Tsukuba, Japan) and cultured in $\alpha$-minimal essential medium (MEM; Sigma-Aldrich; Merck KGaA, Darmstadt, Germany) supplemented with $10 \%$ fetal bovine serum (FBS; SAFC Biosciences, Inc., Lenexa, $\mathrm{KS}, \mathrm{USA}$ ) at $37^{\circ} \mathrm{C}$ in a humidified atmosphere comprising $5 \% \mathrm{CO}_{2}$ in air (18). MC3T3-E1 cells were cultured in $\alpha$-MEM containing $10 \%$ FBS plus $10 \mathrm{mM}$ $\beta$-glycerophosphate (Sigma-Aldrich; Merck KGaA) and $50 \mu \mathrm{g} / \mathrm{ml}$ ascorbic acid (Sigma-Aldrich; Merck KGaA) as the differentiation medium. Cell culture medium was refreshed every 3 days.

Transfection of siRNA. MC3T3-E1 cells were plated $24 \mathrm{~h}$ prior to transfection at a density of $1.7 \times 10^{4}$ cells $/ \mathrm{cm}^{2} /$ well (24-well plate) and cultured in $\alpha$-MEM (Sigma-Aldrich; Merck KGaA) supplemented with 10\% FBS (SAFC Biosciences, Inc.). Then, the cells were transfected with a pre-designed Silencer Select siRNA targeting the Y1 receptor (cat. no. s70765; Ambion; Thermo Fisher Scientific, Inc., Waltham, MA, USA) or Silencer Negative Control siRNA No. 1 (siCont; Ambion; Thermo Fisher Scientific, Inc.) at a concentration of $5 \mathrm{nM}$ using Lipofectamine RNAiMAX Reagent (Invitrogen; Thermo Fisher Scientific, Inc.) for 3 or 6 days, as previously described (19).

Assay of alkaline phosphatase (ALP) activity. MC3T3-E1 cells were plated onto 24 -well plates $24 \mathrm{~h}$ prior to transfection at a density of $1.7 \times 10^{4}$ cells $/ \mathrm{cm}^{2} /$ well. They were then transfected with siY1 or siCont and cultured in $\alpha$-MEM containing $10 \%$ FBS with or without exposure to differentiation medium containing $\beta$-glycerophosphate and ascorbic acid for 3 or 6 days. Following incubation, the cells were washed twice with ice cold PBS, and $200 \mu \mathrm{l}$ of lysis buffer $(10 \mathrm{mM}$ of Tris- $\mathrm{HCl}$, $\mathrm{pH} 8.2$, containing $2 \mathrm{mM}$ of $\mathrm{MgCl}_{2}$ and $0.05 \%$ Triton $\mathrm{X}-100$ ) was added to the cells, which were then kept on ice for $5 \mathrm{~min}$. The cell lysate was sonicated for $1 \mathrm{~min}$ and centrifuged at $1,000 \mathrm{x} \mathrm{g}$ for $10 \mathrm{~min}$ at $4^{\circ} \mathrm{C}$. ALP activity was assayed using a LabAssay ALP kit (Wako Pure Chemical Industries Ltd., Osaka, Japan) according to the manufacturer's instructions. Briefly, $100 \mu 1 p$-nitrophenyl phosphate substrate was added to $20 \mu \mathrm{l}$ of each sample, and the mixture was incubated for $25 \mathrm{~min}$ at $37^{\circ} \mathrm{C}$. The reaction was terminated by the addition of $80 \mu 10.2 \mathrm{M} \mathrm{NaOH}$. The optical density at $405 \mathrm{~nm}$ was measured using an iMark Microplate Absorbance Reader (Bio-Rad Laboratories, Inc., Hercules, CA, USA). Total cell protein was measured using the Bio-Rad Protein assay kit
(Bio-Rad Laboratories, Inc.), and the results were expressed as the concentration of $p$-nitrophenol (nmol) produced/min $/ \mathrm{mg}$ protein.

MC3T3-E1 cells were plated onto 24-well plates $24 \mathrm{~h}$ prior to transfection at a density of $1.7 \times 10^{4}$ cells $/ \mathrm{cm}^{2} /$ well. They were then transfected with siY1 or siCont and cultured in $\alpha$-MEM for 6 days. ALP staining was performed as previously described (18). Briefly, cells in 24-well plates were rinsed in PBS, fixed in $10 \%$ formalin at room temperature for $1 \mathrm{~h}$, rinsed again with PBS, and then overlaid with $300 \mu 1$ 5-bromo-4-chloro-3-indolylphosphate $(0.15 \mathrm{mg} / \mathrm{ml})$ and $0.3 \mathrm{mg} / \mathrm{ml}$ nitro-blue tetrazolium (Wako Pure Chemical Industries, Ltd.) in $0.1 \mathrm{M}$ Tris- $\mathrm{HCl}$ ( $\mathrm{pH} 9.0), 0.01 \mathrm{~N} \mathrm{NaOH}$, and $0.05 \mathrm{mM} \mathrm{MgCl} 2$ prior to incubation at room temperature for $1 \mathrm{~h}$. Images were captured using a digital iPhone 4 camera (Apple Inc., Cupertino, CA, USA), with the same settings applied to all experimental samples.

Von Kossa staining. Matrix mineralization was analyzed by von Kossa staining. MC3T3-E1 cells were plated onto 24-well plates $24 \mathrm{~h}$ prior to transfection at a density of $1.7 \times 10^{4}$ cells $/ \mathrm{cm}^{2} /$ well. They were then transfected with siY1 or siCont and cultured in $\alpha$-MEM for 6 days. Cells in 24-well plates were washed twice with PBS and then fixed in $10 \%$ neutral buffered formalin at room temperature for $30 \mathrm{~min}$. Following three washes with deionized water, mineralized matrix was detected by treating fixed cells with $5 \%$ silver nitrate for $12 \mathrm{~h}$ under ultraviolet light at room temperature. The formation of calcium phosphate deposits was then visualized. Images were acquired using a digital iPhone4 camera (Apple Inc.) with the same settings applied to all experimental samples.

Quantification of gene expression by reverse transcription-quantitative polymerase chain reaction ( $R T-q P C R)$. MC3T3-E1 cells were plated onto 24-well plates $24 \mathrm{~h}$ prior to transfection at a density of $1.7 \times 10^{4}$ cells $/ \mathrm{cm}^{2} /$ well. They were then transfected with siY1 or siCont and cultured in $\alpha$-MEM for 1, 2 or 6 days. Total RNA was extracted from cells in 24-well plate using ISOGEN (Nippon Gene Co., Ltd., Tokyo, Japan) as previously described (18). RNA was quantified by spectrophotometric $\mathrm{OD}_{260}$ measurements and quality was assessed by the $\mathrm{OD}_{260} / \mathrm{OD}_{280}$ and $\mathrm{OD}_{230} / \mathrm{OD}_{280}$ ratios using a NanoDrop spectrophotometer (ND-1000; Thermo Fisher Scientific, Inc.). RT-PCR was performed using a high-capacity cDNA reverse transcription kit (Applied Biosystems; Thermo Fisher Scientific, Inc.) according to the manufacturer's instructions. The resultant cDNA was then used as the template for a PCR. qPCR was performed using assay-on-demand TaqMan Gene Expression assays (Applied Biosystems; Thermo Fisher Scientific, Inc.) and the following primers: Y1 receptor (cat. no. Mm00650798_g1), ALP (cat. no. Mm00475834_m1), osteocalcin (cat. no. Mm03413826_ $\mathrm{mH}$ ), collagen (I) $\alpha 1$ (col1 $\alpha$; cat. no. Mm00801666_g1), bone sialoprotein (BSP; cat. no. Mm00492555_m1), Runx2 (cat. no. Mm00501584_m1), osterix (cat. no. Mm00504574_m1) and GAPDH (Pre-Developed TaqMan Assay Reagents mouse GAPDH no. 4352661; all from Applied Biosystems; Thermo Fisher Scientific, Inc.). A StepOne Real-Time PCR System (Applied Biosystems; Thermo Fisher Scientific, Inc.) was 

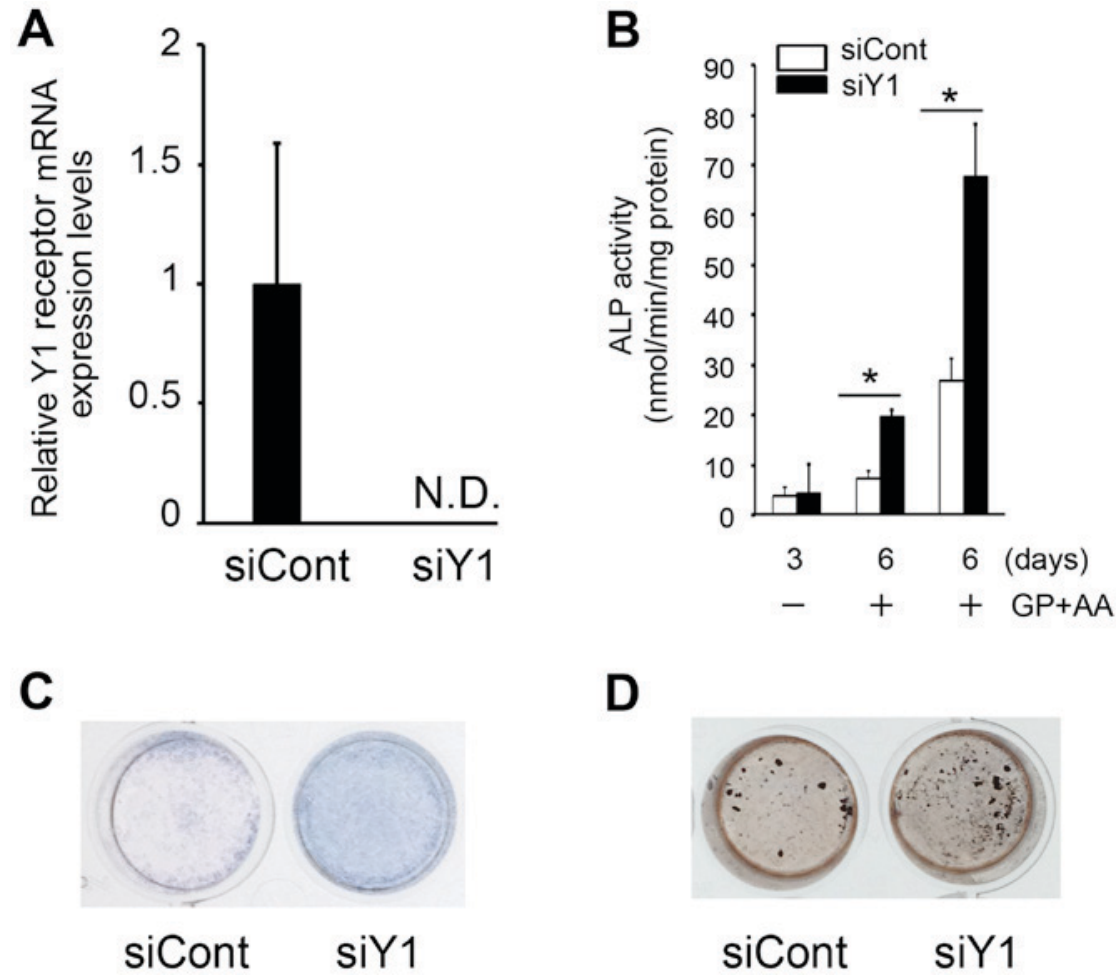

Figure 1. Knockdown of the Y1 receptor induces ALP activity and mineralization in MC3T3-E1 cells. (A) The mRNA levels of the Y1 receptor in MC3T3-E1 cells transiently transfected with siY1 or siCont and incubated for 3 days. (B) ALP activity in MC3T3-E1 cells at 3 and 6 days following transfection with siY1 or siCont and with or without exposure to differentiation medium containing GP and AA. (C) Staining of ALP activity in MC3T3-E1 cells at 6 days following transfection with siY1 or siCont. (D) Matrix calcification was detected in cells at 6 days following transfection by von Kossa staining. Each assay represents a separate experiment performed in triplicate. The results are presented as the mean \pm standard deviation. ${ }^{*} \mathrm{P}<0.05$, as indicated. ALP, alkaline phosphatase; siY1, small interfering RNA targeting the Y1 receptor; siCont, siRNA control; GP, $\beta$-glycerophosphate; AA, ascorbic acid; N.D., not detected.

used with the following cycling conditions: $95^{\circ} \mathrm{C}$ for $10 \mathrm{~min}$, then 40 cycles of $95^{\circ} \mathrm{C}$ for $15 \mathrm{sec}$ and $60^{\circ} \mathrm{C}$ for $1 \mathrm{~min}$, as previously described (19). The relative level of target gene expression was quantified using the comparative quantification cycle method (20), with GAPDH as the endogenous control. The relative expression level of target gene mRNA in the siCont-transfected group on day 2 was defined as the standard.

Analysis of cell viability. MC3T3-E1 cells were plated at $0.9 \times 10^{4}$ cells $/ \mathrm{cm}^{2}$ and following $24 \mathrm{~h}$ of culture, cells were transfected with siY1 or siCont (both at $5 \mathrm{nM}$ ) and incubated again for 1 day. To quantify the number of viable cells, the tetrazolium-based colorimetric Cell Counting kit- 8 assay (Dojindo Molecular Technologies, Inc., Kumamoto, Japan) was employed. A $30 \mu 1$ aliquot of the WST- 8 substrate [5 mM; 2-(2-methoxy-4-nitrophenyl)-3-(4-nitrophenyl)-5-(2, 4-disulfophenyl)-2H-tetrazolium monosodium salt] was added to each well. Following incubation for $1 \mathrm{~h}$ at $37^{\circ} \mathrm{C}$, the optical density was measured at a wavelength of $450 \mathrm{~nm}$ using the iMark Microplate Absorbance Reader (Bio-Rad Laboratories Inc.).

Measurement of caspase-3/7 activity. MC3T3-E1 cells were plated at $1.7 \times 10^{4}$ cells $/ \mathrm{cm}^{2}$ and following culture for $24 \mathrm{~h}$, cells were transfected with siY1 or siCont (both at $5 \mathrm{nM}$ ) and incubated again for 1 day. The cellular enzymatic activities of caspase-3/7 were determined using Caspase-Glo 3/7 assay Systems (Promega Corporation, Madison, WI, USA) as previously described (21). For each reaction, cells were incubated with a luminogenic substrate containing the Asp-Glu-Val-Asp sequence, which is cleaved by activated caspase-3/7, for $1 \mathrm{~h}$ at room temperature. Luminescence was quantified using the MiniLumat LB 9506 Luminometer (Berthold Technologies GmbH and Co., KG, Bad Wildbad, Germany).

Statistical analysis. All experiments were repeated between three and six times, and the representative results are presented as the mean \pm standard deviation. The results were analyzed using the F-test followed by Student's t-test using Microsoft Excel 2010 (Microsoft Corporation, Redmond, WA, USA). $\mathrm{P}<0.05$ was considered to indicate a statistically significant difference.

\section{Results}

Knockdown of the $Y 1$ receptor induces ALP activity and mineralization of MC3T3-E1 cells. To evaluate the potential role of Y1 receptor in osteoblasts, the well-characterized mouse calvaria-derived pre-osteoblastic cell line, MC3T3-E1, was employed. The effect of Y1 receptor knockdown using RNA interference was then investigated. Following transfection of MC3T3-E1 cells with siRNA targeting the Y1 receptor the mRNA expression levels of the $\mathrm{Y} 1$ receptor were reduced to undetectable levels, which confirmed that the siRNA was effective in silencing the endogenous Y1 receptor (Fig. 1A). In these cells, ALP activity was significantly increased at day 6 following Y1 receptor inhibition when compared with siCont-transfected controls (Fig. 1B and C). In order to 

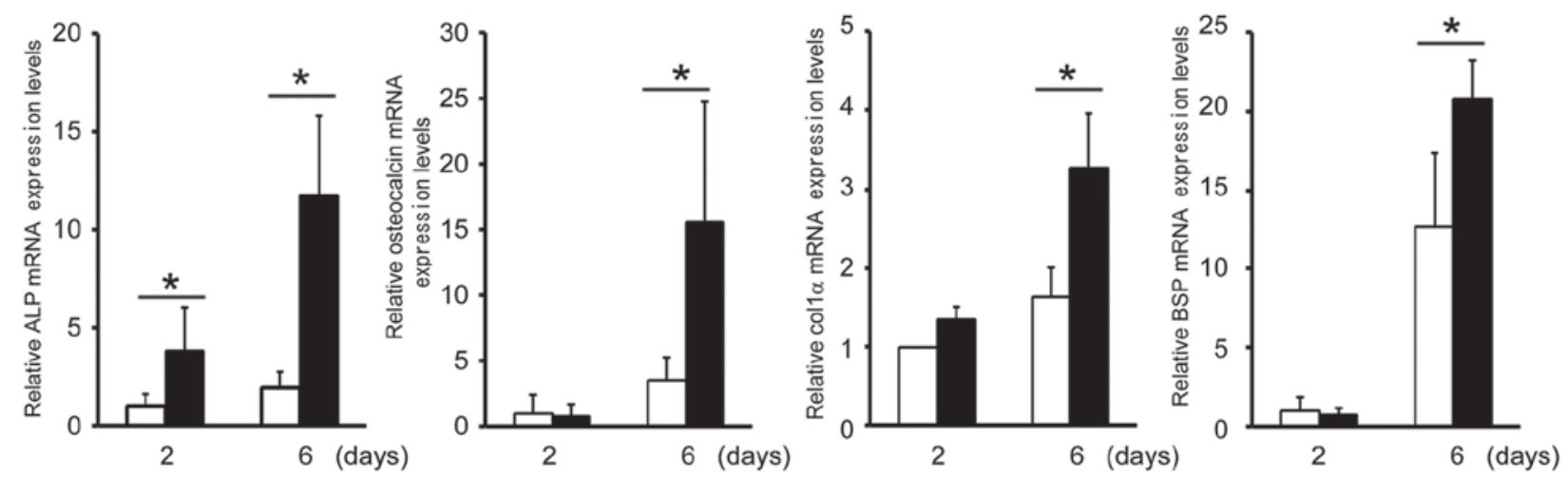

Figure 2. Knockdown of the Y1 receptor upregulates the mRNA expression of specific genes that characterize osteoblastic differentiation in MC3T3-E1 cells. Reverse transcription-quantitative polymerase chain reaction analysis of ALP, osteocalcin, coll $\alpha$ and BSP in MC3T3-E1 cells at 2 or 6 days following transfection with $5 \mathrm{nM}$ siY1 or $5 \mathrm{nM}$ siCont. The results are presented as the mean \pm standard deviation $(\mathrm{n}=3)$. ${ }^{*} \mathrm{P}<0.05$, as indicated. ALP, alkaline phosphatase; coll $\alpha$, collagen (I) $\alpha$; BSP, bone sialoprotein; siY1, small interfering RNA targeting the Y1 receptor; siCont, siRNA control.

determine the effects of $\mathrm{Y} 1$ receptor inhibition, the level of cell matrix mineralization in vitro was examined. Von Kossa staining demonstrated that the mineralization of MC3T3-E1 cells was augmented at day 6 following silencing of the Y1 receptor compared with siCont-transfected controls (Fig. 1D). These results indicate that ALP expression may be Y1 receptor-dependent, and that the NPY signaling pathway may be involved in regulating ALP expression and mineralization in MC3T3-E1 cells.

Knockdown of Y1 receptor upregulates mRNA expression of specific genes that characterize osteoblastic differentiation in MC3T3-El cells. The next aim of the present study was to examine the effects of $\mathrm{Y} 1$ receptor inhibition on the mRNA expression levels of specific genes in MC3T3-E1 cells that characterize osteoblastic differentiation. The mRNA expression levels of ALP, osteocalcin, coll $\alpha$ and BSP were significantly increased in siY1-transfected cells when compared with controls (Fig. 2), which indicated that osteoblastic gene expression may be dependent on Y1 receptor expression. These observations suggest that NPY signaling may be involved in regulating osteoblastic differentiation.

Knockdown of the Y1 receptor upregulates the mRNA expression levels of runt-related transcription factor 2 (Runx2) and osterix in MC3T3-E1 cells. The differentiation and function of osteoblasts is regulated by important transcription factors, such Runx2 and osterix (22). To investigate the mechanism by which Y1 receptor inhibition activates osteoblastic differentiation in MC3T3-E1 cells, the expression level of these transcription factors was examined. As demonstrated in Fig. 3, Runx 2 and osterix mRNA expression levels were significantly upregulated following siRNA-mediated knockdown of the Y1 receptor.

Knockdown of the Y1 receptor does not affect the viability or apoptosis levels in MC3T3-E1 cells. The effect of Y1 receptor expression downregulation on the viability of MC3T3-E1 osteoblasts was then examined. As demonstrated in Fig. 4A, transfection of MC3T3-E1 with siY1 demonstrated no significant effect on cell viability when compared with siCont-transfected controls. Similarly, caspase-3/7 activity, which is activated upon
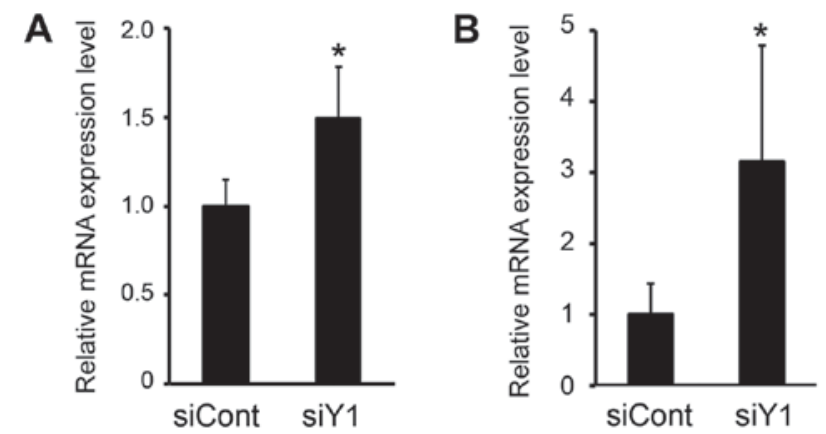

Figure 3. Knockdown of the Y1 receptor upregulates the mRNA expression levels of (A) Runx2 and (B) osterix in MC3T3-E1 cells at 2 days following transfection with siY1 when compared with siCont-transfected cells. The results are presented as the mean \pm standard deviation $(n=3)$. ${ }^{*} \mathrm{P}<0.05$ vs. siCont. Runx2, runt-related transcription factor 2; siY1, small interfering RNA targeting the Y1 receptor; siCont, siRNA control.
A

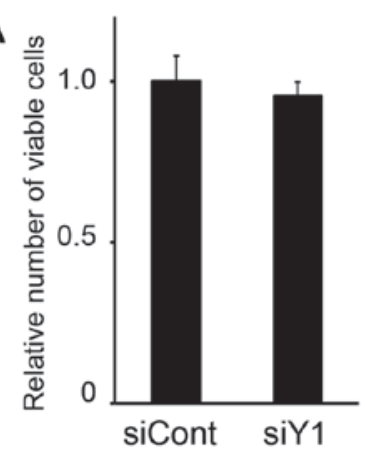

B

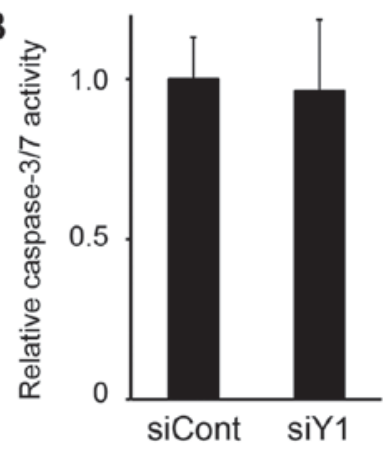

Figure 4. Knockdown of the Y1 receptor does not affect (A) the viability or (B) the level of caspase-3/7 activity in MC3T3-E1 osteoblasts at 1 day following transfection with siY1 compared with siCont-transfected controls. The fold-increase in the number of viable cells or activity of caspase-3/7 activity was calculated relative to siCont-transfected cells. The results are presented as the mean \pm standard deviation $(n=3)$. siY1, small interfering RNA targeting the Y1 receptor; siCont, siRNA control.

apoptosis induction, was not observed to increase following knockdown of the Y1 receptor (Fig. 4B). Therefore, upregulation of osteoblastic gene expression did not appear to be influenced by cell cycle regulation or apoptosis induction. 


\section{Discussion}

The Y1 receptor is a G-protein-coupled receptor predominantly expressed in the brain and in several types of peripheral tissues and cells, such as osteoblasts $(9,16)$. C2C12 cells, a myoblastic cell line with a well-characterized model system, have been reported to differentiate into myotubes and also osteoblasts depending upon the specific culture conditions when incubated with BMP2 (18). A previous study demonstrated that $\mathrm{C} 2 \mathrm{C} 12$ cells do not express $\mathrm{Y} 1$ receptor mRNA; however, its expression is induced by BMP2 treatment, which suggests that induction of Y1 receptor expression may be regulated during the osteoblast differentiation process (15). The results of the present study demonstrated that Y1 receptor inhibition in MC3T3-E1 cells induced osteoblastic differentiation, which may support the notion that Y1 receptor expression may be a marker of osteoblast differentiation.

Several in vitro and in vivo studies have demonstrated that NPY inhibits osteoblast differentiation, which were summarized by Khor and Baldock (7). In bone marrow stromal cells, NPY decreases ALP and osteocalcin expression and inhibits mineralization (23). In a mouse with osteoblast lineage-specific NPY overexpression, trabecular and cortical bone volumes were reduced (24). In addition, decreased expression of osteocalcin was observed in the calvarial osteoblasts of this mouse. Bone marrow stromal cells derived from mice with a germline deletion of the Y1 receptor were investigated (16). Consistent with the results of the present study, Y1 receptor deficiency was observed to enhance osteoblastic differentiation in mesenchymal progenitor cells (16). In the current study, the mRNA expression levels of Runx 2 and osterix, which are two transcription factors that are essential for osteoblastic differentiation and bone formation, were induced by inhibition of the Y1 receptor. Runx2 is now known to be the earliest principle transcription factor involved in the expression of osteoblast-specific genes and in the differentiation of mesenchymal stem cells into osteoblasts (22). In addition, it is thought to function primarily during the terminal differentiation of osteoblasts (25). Inhibition of the Y1 receptor may induce Runx 2 and osterix activities; consequently, it may contribute to osteoblastic differentiation and the expression of ALP, osteocalcin, coll $\alpha$, and BSP (22). In the present study, inhibition of the Y1 receptor using siRNA was observed to regulate ALP activity and mineralization in MC3T3-E1 cells. Together, these results suggest that the Y1 receptor may additionally be involved in inhibiting mineral deposition by mature osteoblasts.

It is known that multiple sources of NPY regulate bone homeostasis. In the peripheral nervous system, NPY is co-stored and co-released with noradrenaline during nerve stimulation (3). In addition, NPY is released into the circulation by sympathetic nerves and the adrenal medulla (3). Furthermore, NPY has been detected in bone tissues, including osteoblasts and osteocytes (14). The results of the current study demonstrated that inhibition of the Y1 receptor induces the expression of differentiation-specific genes in MC3T3-E1 osteoblasts, indicating a role of the local NPY-Y1 receptor axis in regulating osteoblastic differentiation.

A previous study demonstrated that $\mathrm{Y} 1$ receptor antagonism induced by oral administration of BIBO3304
[(R)-N-[[4-(ami-nocarbonylaminomethyl)phenyl]methyl]-N2(diphenylacetyl)-argininamide trifluoroacetate], an argininamide derivative originally developed as a selective $\mathrm{Y} 1$ receptor antagonist, enhanced osteoblast activity in mice (26). This lead to increased mineral deposition rates in the cortical and cancellous bones. In addition, oral administration of BIBO3304 was not observed to produce significant extraskeletal side effects with regards to body weight, energy metabolism, glucose homeostasis or food intake (26). It is hypothesized that a potent Y1 receptor inhibitor or siRNA may be a novel anabolic agent that may be used as a therapeutic agent to prevent or reverse bone loss in conditions such as osteoporosis, through the modulation of osteoblastic activity.

In conclusion, the results of the current study demonstrated that inhibition of the Y1 receptor might enhance osteoblastic differentiation. These results provide an explanation for the mechanism of action of NPY and the Y1 receptor in mediating osteoblast differentiation, and support a potential role of $\mathrm{Y} 1$ receptor inhibition as a novel anabolic strategy for the prevention of bone loss.

\section{Acknowledgements}

The authors would like to thank Dr Kiyomi Tsuji-Tamura (Hokkaido University, Sapporo, Japan) for the critical reading of this manuscript and for her valuable suggestions.

\section{References}

1. Baraban SC: Neuropeptide $\mathrm{Y}$ and limbic seizures. Rev Neurosci 9: 117-128, 1998.

2. Cerdá-Reverter JM and Larhammar D: Neuropeptide Y family of peptides: Structure, anatomical expression, function, and molecular evolution. Biochem Cell Biol 78: 371-392, 2000.

3. Silva AP, Cavadas C and Grouzmann E: Neuropeptide Y and its receptors as potential therapeutic drug targets. Clin Chim Acta 326: 3-25, 2002.

4. Kuo LE, Kitlinska JB, Tilan JU, Li L, Baker SB, Johnson MD, Lee EW, Burnett MS, Fricke ST, Kvetnansky R, et al: Neuropeptide $\mathrm{Y}$ acts directly in the periphery on fat tissue and mediates stress-induced obesity and metabolic syndrome. Nat Med 13: 803-811, 2007.

5. Baldock PA, Allison SJ, Lundberg P, Lee NJ, Slack K, Lin EJ, Enriquez RF, McDonald MM, Zhang L, During MJ, et al: Novel role of Y1 receptors in the coordinated regulation of bone and energy homeostasis. J Biol Chem 282: 19092-19102, 2007.

6. Yang K, Guan H, Arany E, Hill DJ and Cao X: Neuropeptide Y is produced in visceral adipose tissue and promotes proliferation of adipocyte precursor cells via the Y1 receptor. FASEB J 22: 2452-2464, 2008.

7. Khor EC and Baldock P: The NPY system and its neural and neuroendocrine regulation of bone. Curr Osteoporos Rep 10: $160-168,2012$

8. Horsnell $\mathrm{H}$ and Baldock PA: Osteoblastic actions of the neuropeptide Y system to regulate bone and energy homeostasis. Curr Osteoporos Rep 14: 26-31, 2016.

9. Lin S, Boey D and Herzog H: NPY and Y receptors: Lessons from transgenic and knockout models. Neuropeptides 38: 189-200, 2004.

10. Allison SJ, Baldock PA and Herzog H: The control of bone remodeling by neuropeptide Y receptors. Peptides 28: 320-325, 2007.

11. Baldock PA, Sainsbury A, Couzens M, Enriquez RF, Thomas GP, Gardiner EM and Herzog H: Hypothalamic Y2 receptors regulate bone formation. J Clin Invest 109: 915-921, 2002.

12. Shi YC, Lin S, Wong IP, Baldock PA, Aljanova A, Enriquez RF, CastilloL, Mitchell NF, Ye JM,Zhang L, et al: NPY neuron-specific Y2 receptors regulate adipose tissue and trabecular bone but not cortical bone homeostasis in mice. PLoS One 5: e11361, 2010. 
13. Lundberg P, Allison SJ, Lee NJ, Baldock PA, Brouard N, Rost S, Enriquez RF, Sainsbury A, Lamghari M, Simmons P, et al: Greater bone formation of Y2 knockout mice is associated with increased osteoprogenitor numbers and altered Y1 receptor expression. J Biol Chem 282: 19082-19091, 2007.

14. Igwe JC, Jiang X, Paic F, Ma L, Adams DJ, Baldock PA, Pilbeam CC and Kalajzic I: Neuropeptide Y is expressed by osteocytes and can inhibit osteoblastic activity. J Cell Biochem 108: 621-630, 2009.

15. Kurebayashi N, Sato M, Fujisawa T, Fukushima K and Tamura M: Regulation of neuropeptide Y Y1 receptor expression by bone morphogenetic protein 2 in $\mathrm{C} 2 \mathrm{C} 12$ myoblasts. Biochem Biophys Res Commun 439: 506-510, 2013.

16. Lee NJ, Nguyen AD, Enriquez RF, Doyle KL, Sainsbury A, Baldock PA and Herzog H: Osteoblast specific Y1 receptor deletion enhances bone mass. Bone 48: 461-467, 2011.

17. Bjurholm A, Kreicbergs A, Schultzberg $M$ and Lerner UH: Parathyroid hormone and noradrenaline-induced enhancement of cyclic AMP in a cloned osteogenic sarcoma cell line (UMR 106) is inhibited by neuropeptide Y. Acta Physiol Scand 134: 451-452, 1988.

18. Nakashima A, Katagiri $\mathrm{T}$ and Tamura M: Cross-talk between Wnt and bone morphogenetic protein 2 (BMP-2) signaling in differentiation pathway of C2C12 myoblasts. J Biol Chem 280: 37660-37668, 2005.

19. Uyama M, Sato MM, Kawanami M and Tamura M: Regulation of osteoblastic differentiation by the proteasome inhibitor bortezomib. Genes Cells 17: 548-558, 2012.
20. Livak KJ and Schmittgen TD: Analysis of relative gene expression data using real-time quantitative PCR and the 2(-Delta Delta C(T)) method. Methods 25: 402-408, 2001.

21. Iizuka S, Oridate N, Nashimoto M, Fukuda S and Tamura M: Growth inhibition of head and neck squamous cell carcinoma cells by sgRNA targeting the cyclin D1 mRNA based on TRUE gene silencing. PLoS One 9: e114121, 2014.

22. Karsenty G: Transcriptional control of skeletogenesis. Annu Rey Genomics Hum Genet 9: 183-196, 2008.

23. Teixeira L, Sousa DM, Nunes AF, Sousa MM, Herzog H and Lamghari M: NPY revealed as a critical modulator of osteoblast function in vitro: New insights into the role of Y1 and Y2 receptors. J Cell Biochem 107: 908-916, 2009.

24. Matic I, Matthews BG, Kizivat T, Igwe JC, Marijanovic I, Ruohonen ST, Savontaus E, Adams DJ and Kalajzic I: Bone-specific overexpression of NPY modulates osteogenesis. J Musculoskelet Neuronal Interact 12: 209-218, 2012.

25. Ryoo HM, Lee MH and Kim YJ: Critical molecular switches involved in BMP-2-induced osteogenic differentiation of mesenchymal cells. Gene 366: 51-57, 2006.

26. Sousa DM, Baldock PA, Enriquez RF, Zhang L, Sainsbury A, Lamghari M and Herzog H: Neuropeptide Y Y1 receptor antagonism increases bone mass in mice. Bone 51: 8-16, 2012. 